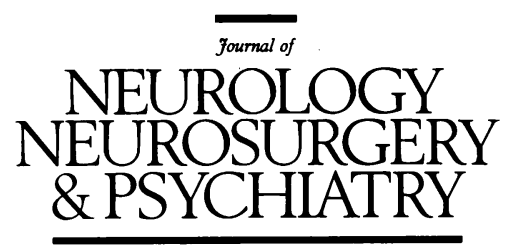

Editorial

\title{
Myelin gene dosage and mutation in the hereditary motor and sensory neuropathies: a review
}

Application of molecular biology techniques has led to rapid advances in the area of hereditary neuropathies, particularly in the group of disorders with slow nerve conduction velocities associated with demyelination or hypomyelination. This heterogeneous group is generally recognised as Charcot-Marie-Tooth or hereditary motor and sensory neuropathy (CMT or HMSN type I). The nomenclature of the Charcot-Marie-Tooth disorders is still evolving. The neurological literature uses a combination of electrophysiological and genetic criteria to classify these disorders as HMSN or CMT type I. ${ }^{1} \mathrm{HMSN}$ III, (Dejerine-Sottas disease) is phenotypically severe and is thought to be recessively inherited. It can no longer be regarded as a single disease entity as cases with the same dominant mutations as found in CMT1A and CMT1B have been identified and a case of presumed homozygous HMSN type II was reported with the Dejerine-Sottas phenotype. $^{2}$

The genetic literature refers to the hereditary neuropathies with slow nerve conduction velocities according to their chromosomal loci on chromosomes 17 and 1 and the $\mathrm{X}$ chromosome as CMT1A, $1 \mathrm{~B}$, and CMTX respectively. This classification may be expanded to describe gene mutations as more mutations are found. In this review, CMT type I has been used in place of the term HMSN I to correspond with the genetic nomenclature.

The genes involved in the CMT syndromes with slow nerve conduction velocities (CMT type I) were found by "reverse genetics", an originally unfashionable approach, now called positional cloning. This approach uses many DNA markers covering the whole human genome looking for linkage of the disease to a particular marker. This strategy has often produced unexpected findings that could never have been achieved by traditional research methods such as searching for a defective protein. In the case of CMT, a search for a protein defect would have been fruitless as the most common form (CMT1A) has no abnormal protein.

In 1993, the first gene involved in producing the CMT phenotype was found. This was the result of a rapid series of advances that followed mapping of the locus for most CMT type I families to chromosome 17 in $1989 .^{3}$ Positional cloning led to the discovery of a submicroscopic DNA duplication in patients with CMT1A, of about 1.5 million bases ${ }^{4-6}$ containing an additional copy of a newly recognised myelin gene, PMP22. ${ }^{7-10}$ Two large DNA repeat regions were found to flank the region liable to duplication. These repeats are likely to predispose to unequal crossing over causing duplication and deletion events. ${ }^{11}$ Support for this mechanism was provided when a DNA deletion of the same size as the CMT1A duplication was found in hereditary neuropathy with liability to pressure palsy (HNPP). ${ }^{12}$

The proof that PMP22 was the gene involved in CMT was provided when two rare non-duplicated CMT type I families, which linked to chromosome 17, were found with point mutations in the PMP22 gene. ${ }^{13}{ }^{14}$ One of these, the Dutch family, has slower conduction velocities than found in patients with CMT1A duplication and has a sural nerve biopsy resembling HMSN III. ${ }^{13}$ This family has the same mutation as the trembler mouse, which has similar pathological changes as HMSN III. ${ }^{15}$

It is thought that the additional copy of PMP22 in patients with CMT1A duplication leads to overdose of the gene product. ${ }^{16}$ This is the first example of a disease being caused by an additional copy of a normal gene. Direct proof of the dosage effect was obtained when increased PMP22 mRNA concentrations were found in CMT1A biopsies. ${ }^{17}$

Some new questions must now be answered. Can the CMT1A point mutations produce the same effect as gene overdose or is the phenotype different in duplication and mutation patients? Do different point mutations cause functional overdosage or underdosage? What happens if both chromosomes have duplicated, deleted, or mutated copies of CMT genes?

Some clues to the complexities of CMT may be provided by experience in retinitis pigmentosa. For many years it has been known that CMT, like retinitis pigmentosa, is one of a few diseases showing dominant, $\mathrm{X}$ linked, and recessive modes of inheritance. ${ }^{18}$ This suggests involvement of a family of genes with similar functions. This has proved to be true in CMT type I where all mutations found so far involve Schwann cell membrane and myelin proteins; CMT may therefore be similar to retinitis pigmentosa at a molecular level. Two or more proteins may interact between adjacent membranes (in CMT between myelin lamellae and in retinitis 
pigmentosa between photoreceptor discs) explaining how mutations in different proteins can produce a similar syndrome if they are part of the same protein complex.

In some families with retinitis pigmentosa two interacting proteins must be mutated to produce disease. This is a new class of mutations, which on their own may be innocuous but when combined, produce disease. In retinitis pigmentosa, such families have a pattern of inheritance that looks incompletely dominant and have been described as showing digenic inheritance. ${ }^{19}$ Such mutations may cause some of the rarer types of CMT. Interaction with a second protein would also account for PMP22 gene dosage sensitivity; alternatively PMP22 protein may form an ion channel. Mutations altering channel function or giving increased numbers of channels in patients with CMT duplications could also explain gene dosage sensitivity.

Most families $(60 \%-80 \%)$ with severe slowing of motor nerve conduction (HMSN I) have the chromosome 17 form of CMT (CMT1A) ${ }^{20}$ and the mutation in most of these is the DNA duplication. Most of the remaining families $(20 \%-30 \%$ of all families with CMT type I) probably have CMTX. A few families have CMT1B and a similar number are as yet unlocalised (Ionasescu $e t a^{21}$ and author's unpublished results).

Occasionally CMT occurs as a single sporadic case with no other affected family members. Most sporadic cases were found to be new dominant CMT1A mutations. ${ }^{22}$ Severe early onset cases (Dejerine-Sottas disease or HMSN III) were initially thought to be recessive but at least some cases are new dominant PMP22 mutations $^{23}$ or mutations of the $P_{o}$ myelin protein gene. ${ }^{24}$ There are other rare, dominant, ${ }^{25}$ and recessive families whose mutations have not been mapped, so that other CMT type I genes are yet to be found.

The gene mutated in X linked CMT was identified in December 1993, when it was found that the connexin 32 gene mapped into the CMTX region. Subsequently, DNA sequencing revealed mutations in CMTX families. ${ }^{26-28}$ Connexin32 is a gap junction protein and is expressed in the paranodal region in the same location as tight junctions. Connexin may therefore modulate Schwann cell and axon interactions, explaining the mixed axonal and demyelinating biopsy appearances in CMTX.

Many connexin 32 mutations have now been reported. Nearly every family has a different mutation. As frame shift mutations (leading to premature stop codons) ${ }^{26}$ and new stop codon mutations have been reported, it is clear that the CMTX phenotype, unlike CMT1A, is the result of a loss of function, possibly related to axon and myelin maintenance.

One locus for a recessive CMT syndrome has been found on chromosome $8^{29}$ but it seems not to be the $P_{2}$ myelin protein gene locus that is also located on chromosome 8. One case of a presumed recessive PMP22 mutation was described in a PMP22 compound heterozygote (deletion and point mutation). ${ }^{30}$ Recessive mutations of the other myelin genes (PMP22, $\mathrm{P}_{\mathrm{o}}$, and connexin32) have been excluded in four phenotypically different recessive families. ${ }^{31}$

How these mutations in PMP22, connexin32, and $P_{\circ}$ proteins produce disease is unknown but clues can be provided by the CMT mutations, particularly naturally occurring knock out (or null) mutations. Null mutations either delete a gene or prevent transcription by the insertion of a premature stop codon, thus preventing the gene from being fully expressed. Some null mutations have been found in both PMP22 and connexin 32 genes. Surprisingly the PMP22 null mutations are associated with HNPP phenotype and not CMT1A. ${ }^{32}$
Mutations in the proteolipid protein (PLP) gene produce the Pelizaeus-Merzbacher syndrome. This syndrome can rarely be caused by PLP duplications. ${ }^{33}$ The PLP protein has a similar structure to PMP22 and is thought to be its CNS equivalent. This suggests that both myelin genes may be dosage sensitive and a rule may be emerging; that the dominant, mild, CMT type I syndromes are myelin gene dosage disorders where the CMT phenotype is caused by overdosage and the HNPP phenotype results from underdosage. The severe syndromes (cases with severe wasting or requiring wheelchairs in young adulthood) may appear sporadic or be recessive and may be due to point mutations in myelin genes with a different pathogenesis.

One can speculate that $P_{o}$ may also have both gain of function and loss of function mutations. If the effect of dosage of $P_{o}$ is the same as for PMP22, one could predict that mutations leading to loss of $P_{0}$ function or decreased gene expression would produce tomacula. This would explain a report of a CMT1B family with no clinical evidence of pressure sensitivity, which surprisingly had profuse tomacula on sural nerve biopsy. ${ }^{34}$ As in CMT1A, the other CMT1B $P_{\circ}$ point mutations may be gain of function mutations producing the CMT type I phenotype. So far there is no direct evidence for overexpression but a patient with the Dejerine-Sottas phenotype due to a $P_{o}$ point mutation did not have reduced expression or a truncated product. ${ }^{35}$

One $P_{o}$ frame shift (null) mutation was reported as a clinical CMT1B case but it is not known if tomacula were present as a sural nerve biopsy result was not reported. ${ }^{36}$ Clinical diagnosis can be difficult as there is overlap between the CMT and HNPP syndromes. Some families with tomaculous neuropathy on biopsy have been reported with a "CMT" phenotype with pes cavus, slow motor conductions, and no evidence of pressure sensitivity. ${ }^{37}$

If the dosage scheme is true it is hard to see how recessive disorders of the PMP22 and $\mathrm{P}_{0}$ myelin genes can produce a CMT (overdose) syndrome. A recessive PMP22 point mutation (thought to be recessive as subjects with the mutation on its own were normal) combined with a deletion is associated with a severe CMT phenotype. ${ }^{30} \mathrm{~A}$ second apparent exception is a frame shift PMP22 mutation (which should reduce PMP22 expression) associated with a CMT phenotype ${ }^{38}$ Both of these exceptions may be more apparent than real, due to overlap between the HNPP and CMT phenotypes mentioned earlier. ${ }^{37}$

The three or more genes involved in CMT have produced a dilemma for clinicians and laboratories: which test is appropriate for a particular CMT family? The choice can be guided by the results of nerve conduction studies. ${ }^{39} 40$ If the family has normal motor conduction velocities (CMT type II), no DNA tests are yet available. Type I families with very slow nerve conduction velocities should be tested for the CMT1A duplication and if negative should be reassessed clinically for signs of CMTX and CMT1B. CMTX can be recognised by the presence of mildly or unaffected carrier females with intermediate conduction velocities and a pattern of inheritance with no male to male transmission. ${ }^{39}$ These probable CMTX families will require sequencing of the connexin 32 gene.

Dominantly inherited subjects in a family with male to male transmission who lack the CMT1A duplication, may have $P_{o}$ or PMP22 point mutations or a mutation in another as yet undefined gene. Sequencing for these mutations is only available on a research basis. Some families, initially diagnosed as CMT, will have the HNPP 
deletion, which can usually be detected by loss of alleles for markers within the duplication and by specific DNA tests. Sporadic CMT type I cases should be tested for the duplication and if negative, tested for connexin32, PMP22, and $P_{o}$ mutations.

These molecular advances have shown that the mild HNPP syndrome and the more obvious CMT phenotype with slow motor conduction velocities are part of a diverse group of Schwann cell disorders. It is no longer sufficient to make a diagnosis on the clinical phenotype alone. The genotype should be determined by appropriate DNA testing.

In view of the rapid advances over the past few years, it will be surprising if more developments do not occur soon. One future direction for research will be to determine the control mechanisms governing myelin gene dosage, with a view to developing specific treatments for CMT and particularly CMT1A.

University of Sydney, Molecular Medicine Laboratory

GARTH NICHOLSON

Clinical Sciences Building, Concord Hospital,

NSW 2139, Australia

1 Dyck PJ, Chance P, Lebo R, Carney JA. Neuronal atrophy and degeneration predominantly affecting peripheral sensory and autonomic neurones. In: Dyck T, ed. Peripheral neuropathy. Philadelphia: $\mathbb{W}$ B Saunders, 1993:1094-136.

2 Sghirlanzoni A, Pareyson D, Balestrini MR, et al. HMSN-III Phenotype due to homozygous expression of a dominant HMSN-II gene. Neurology 1992;42:2201-3.

3 Vance JM, Nicholson GA, Yamaoka LH, et al. Linkage of Charcot-MarieTooth neuropathy type la to chromosome 17. Exp Neurol 1989;104:186-9.

4 de Visser M. Workshop report: diagnostic criteria for autosomal dominant hereditary motor and sensory neuropathy type Ia. Neuromuscul Disord 1993;3:77-9.

5 Raeymaekers $\dot{P}$, Timmerman V, Nelis E, et al. Duplication in chromosome $17 \mathrm{p} 11 \cdot 2$ in Charcot-Marie-Tooth neuropathy type 1a (CMT 1A). Some $17 \mathrm{p} 11 \cdot 2$ in Charcot-Marie-

6 Lupski JR, Montes de Oca-Luna R, Slaugenhaupt S, et al. DNA duplication associated with Charcot-Marie-Tooth disease type 1A. Cell 1991;66:219-32.

7 Patel PI, Roa BB, Welcher AA, et al. The gene for the peripheral myelin protein PMP-22 is a candidate for Charcot-Marie-Tooth disease type 1A. Nature Genetics 1992;1:159-65.

8 Valentijn LJ, Bolhuis PA, Zorn I, et al. The peripheral myelin gene PMP$22 /$ GAS-3 is duplicated in Charcot-Marie-Tooth disease type $1 \mathrm{~A}$. Nature Genetics 1992;1:166-70.

9 Matsunami N, Smith B, Ballard L, et al. Peripheral mylein protein-22 gene maps in the duplication in chromosome $17 \mathrm{pl1.2}$ associated with Charcot-Marie-Tooth 1A. Nature Genetics 1992;1:176-9.

10 Timmerman V, Nelis E, Van Hul W, et al. The peripheral myelin protein gene PMP-22 is contained within the Charcot-Marie-Tooth disease gene PMP-22 is contained within the Charcot-Mat
type 1A duplication. Nature Genetics 1992;1:171-5.

11 Pentao L, Wise CA, Chinault AC, et al. Charcot-Marie-Tooth type 1A duplication appears to arise from recombination at repeat sequences flanking the 1.5 Mb monomer unit. Nature Genetics 1992;2:292-300.

12 Chance PF, Alderson MK, Leppig KA, et al. DNA deletion associated with hereditary neuropathy with liability to pressure palsies. Cell 1993;72:143-51

13 Valentijn LJ, Bass F, Wolterman RA, et al. Identical point mutations of PMP-22 in Trembler-J mouse and Charcot-Marie-Tooth disease type 1A. Nature Genetics 1992;2:288-91.

14 Roa BB, Garcia CA, Suter U, et al. Charcot-Marie-Tooth disease type-1A association with a spontaneous point mutation in the PMP22 gene. $N$ Engl f Med 1993;329:96-101.
15 Ayers MM, Anderson RM. Onion bulb neuropathy in the Trembler mouse: a model of hypertrophic interstitial neuropathy (DejerineSottas) in man. Acta Neuropathol (Berl) 1973;25:54-70.

16 Lupski JR, Wise CA, Kuwano A, et al. Gene dosage is a mechanism for Charcot-Marie-Tooth disease type 1A. Nature Genetics 1992;1:29-33.

17 Hanemann CO, Stoll G, D'Urso D, et al. Peripheral myelin protein-22 expression in Charcot-Marie-Tooth disease type la sural nerve biopsies. f Neurosci Res 1994;37:654-9.

18 McKusick VA. 118200 Charcot-Marie-Tooth disease. Mendelian inheritance in man. Baltimore: The Johns Hopkins University Press 1992:211-4.

19 Kajiwara K, Berson EL, Dryja TP. Digenic retinitis pigmentosa due to mutations at the unlinked. Peripherin/RDS and ROM1 loci. Science 1994;264:1064-7

20 Wise CA, Garcia CA, Davis SN, et al. Molecular analyses of unrelated Charcot-Marie-Tooth (CMT) disease patients suggest a high frequency Charcot-Marie-Tooth (CMT) disease patients suggest a high freq
of the CMTIA duplication. Am $₹$ Hum Genet 1993;53:853-63.

21 Ionasescu VV, Ionasescu R, Searby BS. Screening of dominantly inherited Charcot-Marie-Tooth neuropathies. Muscle Nerve 1993;16:1232-8.

22 Hoogendijk JE, Hensels GW, Gabreelsfesten AAWM, et al. De novo mutation in hereditary motor and sensory neuropathy type 1. Lancet 1992;339:1081-2.

23 Roa BB, Dyck PJ, Marks HG, Chance PF, Lupski JR. Dejerine-Sottas syndrome associated with point mutation in the peripheral myelin protein 22 (PMP 22) gene. Nature Genetics 1993;5:269-72.

24 Hayasaka $\mathrm{K}$, Himoro $M$, Sawaishi $\mathrm{Y}$, et al. De-novo mutation of the myelin Po gene in hereditary motor and sensory neuropathy type III (Dejerine-Sottas disease). Nature Genetics 1993;5:266-8.

25 Chance PF, Bird TD, O'Connell P, Lipe H, Lalouel J-M, Leppert M. Genetic linkage and heterogeneity in type 1 Charcot-Marie-Tooth disease (hereditary motor and sensory neuropathy type 1). Am f Hum Genet 1990;47:915-25.

26 Bergoffen J, Scherer SS, Wang S, et al. Connexin mutations in X-linked Charcot-Marie-Tooth disease. Science 1993;262:2039-42.

27 Hayasaka $\mathrm{K}$, Himoro $M$, Sato $\mathbb{W}$, et al. Charcot-Marie-Tooth type $1 \mathrm{~B}$ is associated with mutations of the myelin $P_{0}$ gene. Nature Genetics 1993;5:31-4.

28 Kulkens T, Bolhuis PA, Wolterman RA, et al. Deletion of the serine 34 codon from the major peripheral myelin $P_{0}$ gene in Charcot-MarieTooth disease type 1B. Nature Genetics 1993;5:35-9.

29 Ben Othmane K, Henati F, Lennon F, et al. Linkage of a locus (CMT4A) for autosomal recessive Charcot-Marie-Tooth disease to chromosome 8q. Hum Mol Genet 1993;2:1625-8.

30 Roa BB, Garcia CA, Pentao L, et al. Evidence for a recessive PMP22 point mutation in Charcot-Marie-Tooth disease type 1A. Nature point mutation in Charcs $1993 ; 5: 189-94$.

31 Mariman E, Gabreels-Festen A, van Beersum S, Ropers H-H, Jongen P, Gabreels F. Genetic and molecular analysis of families with morphologically different subtypes of autosomal recessive demylinating HMSN. Muscle Nerve 1994;1(suppl):S230.

32 Nicholson GA, Valentijn LJ, Cherryson AK, et al. A Frame shift mutation in the PMP22 gene in hereditary neuropathy with liability to pressure palsies. Nature Genetics 1994;6:263-6.

33 Ellis D, Malcolm S. Proteolipid protein gene dosage effect in PelizaeusMerzbacher disease. Nature Genetics 1994;6:333-4.

34 Thomas FP, Lebo RV, Rosoklija G, et al. Tomaculous neuropathy in chromosome 1 Charcot-Marie-Tooth syndrome. Acta Neuropathol (Berl) 1994;87:91-7.

35 Tachi N, Kasai K, Chiba S, Naganuma M, Ueymura K, Hayasaka K. Expression of $\mathrm{P}_{0}$ protein in sural nerve of a patient with hereditary Expression of $P_{\circ}$ protein in sural nerve of a patient with hereditary

36 Rautenstrauss B, Nelis E, Grehl H, Van Broekhoven C. European CMT consortium group meeting, Paris, 2 June 1994.

37 Barbieri F, Santangelo R, Crisci C, Ragno M, Perretti A, Santoro L. A family with tomaculous neuropathy mimicking Charcot-Marie-Tooth disease. Clin Neurol Neurosurg 1990;92-3:289-94.

38 Nelis E, Timmerman V, De Jonghe P, Van Broeckhoven C. Identification of a 5' splice site mutation in the PMP-22 gene in autosomal dominan Charcot-Marie-Tooth disease type 1. Hum Mol Genet 1994;3:515-6.

39 Nicholson G, Nash J. Intermediate nerve conduction velocities define $X$ Linked Charcot-Marie-Tooth neuropathy families. Neurolog 1993;43:2558-64.

40 Nicholson GA. Penetrance of the hereditary motor and sensory neuropathy Ia-mutation; assessment by nerve conduction studies. Neurology 1991;41:547-52. 